OPEN ACCESS

Edited by:

Fredrik Schlyter,

Czech University of Life Sciences

Prague, Czechia

Reviewed by:

Göran Åke Olof Birgersson,

Swedish University of Agricultural

Sciences, Sweden

Joachim Ruther,

University of Regensburg, Germany

David Robert Hall,

Natural Resources Institute,

United Kingdom

Jonathan David Sweeney,

Natural Resources Canada, Canadian

Forest Service, Canada

${ }^{*}$ Correspondence:

Jocelyn G. Millar

millar@ucr.edu

Specialty section: This article was submitted to

Chemical Ecology,

a section of the journal

Frontiers in Ecology and Evolution

Received: 11 March 2017

Accepted: 14 August 2017

Published: 29 August 2017

Citation:

Silva WD, Zou Y, Bento JMS,

Hanks LM and Millar JG (2017)

Aggregation-Sex Pheromones and

Likely Pheromones of 11 South

American Cerambycid Beetles, and

Partitioning of Pheromone Channels.

Front. Ecol. Evol. 5:101.

doi: 10.3389/fevo.2017.00101

\section{Aggregation-Sex Pheromones and Likely Pheromones of 11 South American Cerambycid Beetles, and Partitioning of Pheromone Channels}

\author{
Weliton D. Silva ${ }^{1}$, Yunfan Zou ${ }^{2}$, José M. S. Bento ${ }^{1}$, Lawrence M. Hanks ${ }^{3}$ and \\ Jocelyn G. Millar ${ }^{2 *}$
}

\begin{abstract}
${ }^{1}$ Department of Entomology and Acarology, University of São Paulo, Piracicaba, Brazil, ${ }^{2}$ Department of Entomology, University of California, Riverside, Riverside, CA, United States, ${ }^{3}$ Department of Entomology, University of Illinois at Urbana-Champaign, Urbana, IL, United States
\end{abstract}

Over the past decade, volatile sex and/or aggregation pheromones and pheromone candidates have been identified for well over 100 species in the large beetle family Cerambycidae, demonstrating that pheromone-based communication is crucial for effective mate location by these insects. Despite this rapid progress in elucidating the chemical ecology of the Cerambycidae, most research to date has focused on species from North America, Europe, and Asia, with almost nothing known about species native to Africa, Australia, and South America. Here, we report the identification and field assessment of aggregation-sex pheromones produced by adult males of Ambonus distinctus (Newman) and Ambonus electus (Gahan), two sympatric and synchronic cerambycid species endemic to South America. Analyses of headspace volatiles from adult beetles showed that these species share two male-specific components, (R)-3-hydroxyhexan-2-one, and lesser amounts of 1-(1H-pyrrol-2-yl)-1,2-propanedione. Headspace volatiles from male $A$. distinctus also contained a novel minor component, identified as 3-methylthiopropan-1-ol. Field bioassays were conducted in Brazil, testing reconstructed blends of the compounds produced by each species, as well as racemic 3-hydroxyhexan-2-one and 1-(1H-pyrrol-2-yl)-1,2-propanedione as single components. Both sexes of $A$. distinctus and $A$. electus were most attracted to traps baited with their respective blends. In particular, 3-methylthiopropan-1-ol synergized attraction of $A$. distinctus and appeared to antagonize attraction of A. electus, suggesting a mechanism to minimize cross-attraction between these two congeners. Nine other cerambycid species were captured in significant numbers during the bioassays, including Ambonus interrogationis (Blanchard), Amorupi fulvoterminata (Berg), Chrysoprasis aurigena (Germar), Itaclytus olivaceus (Laporte \& Gory), Neoclytus pusillus (Laporte \& Gory), Orthostoma abdominale (Gyllenhal), Sphaerion inerme White, Stizocera consobrina Gounelle, and Uncieburia nigricans (Gounelle). Males of some of these species were found to produce $(R)$-3-hydroxyhexan-2-one, explaining why they 
had been attracted to some of the lures tested in bioassays. However, males of other species produced compounds other than 3-hydroxyhexan-2-one or 1-(1H-pyrrol-2-yl)-1,2-propanedione. We propose that these species are exploiting the pheromones of other guild members to locate high quality hosts for their larvae.

Keywords: Coleoptera, longhorn beetles, aggregation-sex pheromones, interspecific attraction, 3-hydroxyhexan2-one, 1-(1H-pyrrol-2-yl)-1,2-propanedione, 3-methylthiopropan-1-ol

\section{INTRODUCTION}

Over the past decade, volatile pheromones and pheromone candidates have been identified for well over 100 beetle species in the five major subfamilies (Prioninae, Lepturinae, Spondylidinae, Lamiinae, and Cerambycinae) of the family Cerambycidae, demonstrating that these types of semiochemicals are widely used for mate location by these beetles (review Hanks and Millar, 2016). The pheromones are of two types: femaleproduced sex pheromones which attract only males, produced by species in the subfamilies Prioninae and Spondylidinae, and male-produced aggregation pheromones which typically attract both sexes, which are found in species in the subfamilies Cerambycinae, Lamiinae, and Spondylidinae. The latter type of pheromone has more recently been referred to as an aggregation-sex pheromone (sensu Cardé, 2014) because its primary function is probably to bring the sexes together for mating.

Accumulating evidence suggests that there is considerable parsimony among cerambycid species with regard to pheromone biosynthesis and use, with closely related species often sharing pheromone components, or even producing pheromones of apparently identical composition (e.g., Hanks et al., 2007; Mitchell et al., 2011, 2013; Ray et al., 2012, 2015; Hanks and Millar, 2013). For example, $\sim 60$ species within the subfamily Cerambycinae have been shown to emit and are attracted to pheromone compounds with 6,8 , or 10 carbon chains, with carbonyl or hydroxyl groups on carbons 2 and/or 3 (listed in Table S1 of Hanks and Millar, 2016). An additional $\sim 30$ cerambycine species have been shown to be strongly attracted to these types of compounds, indicating that the compounds are likely pheromone components for most of these species. However, it has not yet been possible to collect headspace samples from these species to confirm that they are indeed producing the compounds to which they are attracted. In total, these $\sim 100$ species span 18 tribes, indicating that the hydroxyketone/diol motif is highly conserved within the subfamily. It is not yet possible to suggest how the pheromone structures might correlate with cerambycid phylogeny because the relationships among the tribes within the subfamily Cerambycinae have not been resolved.

Because of the sharing of pheromone structures among a number of cerambycine species, it is common to catch several species in traps baited with a single pheromone compound. To limit unproductive attraction to heterospecifics, cross attraction among sympatric cerambycid species may be minimized by a number of mechanisms, including differences between species in seasonal and diel activity patterns, the use of species-specific pheromone blends rather than single components (Mitchell et al., 2015; Meier et al., 2016), and vertical stratification of species within the forest canopy (Graham et al., 2012; Schmeelk et al., 2016).

Despite the recent rapid progress, pheromones have been identified for less than one percent of the $\sim 35,000$ described species within the family (Švácha and Lawrence, 2014). In areas which have been sampled with pheromone-baited traps over a number of years, such as east-central Illinois (Hanks et al., 2014), only a fraction of the native species have been caught, suggesting that other pheromone motifs remain to be discovered. Furthermore, most semiochemical research to date has focused on species native to North America, Europe, and Asia, with almost nothing known about the attractant pheromones of species native to Africa, Australia, and South America, despite the great diversity of cerambycid species native to those continents (e.g., Duffy, 1957, 1960, 1963). For example, in Brazil, $\sim 4,000$ species have been described (Costa, 2000), but volatile pheromones used in mate location have been described for only four species to date: Hedypathes betulinus (Klug) (Fonseca et al., 2010), Eburodacrys vittata (Blanchard) (Silva et al., 2016a), Chlorida costata Audinet-Serville Chlorida festiva (L.) (Silva et al., 2016b).

As part of a project to explore the chemical ecology of the South American Cerambycidae, we report here the identification and field assessment of attractant pheromones emitted by two species, Ambonus distinctus (Newman) and Ambonus electus (Gahan) (Cerambycinae, tribe Elaphidiini). The known range of these species includes Brazil, Paraguay, and Argentina (Monné, 2017). Ambonus distinctus also occurs in French Guiana and Uruguay, whereas A. electus is also known from Colombia, Surinam, and Venezuela (Monné, 2017). In Brazil, larvae of both species develop in trees of the Fabaceae, with hosts of $A$. distinctus including Piptadenia gonoacantha (Mart.) J. F. Macbr. and Parapiptadenia rigida (Benth.) Brenan, whereas hosts of A. electus include a number of Piptadenia species (Silva et al., 1968; Monné, 2001).

During the course of field bioassays testing the possible pheromone components of the two Ambonus species, nine other species of the Cerambycinae were attracted to pheromone-baited traps in significant numbers. Thus, as a follow-on objective, we collected and analyzed the volatiles released by both sexes of seven of these nine species, to determine whether they did indeed share pheromone components with the two target species. 


\section{MATERIALS AND METHODS}

\section{Collection and Identification of Beetle-Produced Volatile Compounds}

Collection of and field experiments with all cerambycid species described below, were conducted under SISBIO permit \#46395-1 and \#46395-2 from the Brazilian Ministry of the Environment. Adult $A$. distinctus and $A$. electus of both sexes (mating status unknown) were caught with panel traps (black corrugated plastic) constructed as described previously (Silva et al., 2016a,b). Internal surfaces of traps were coated with a $50 \%$ aqueous dilution of Fluon ${ }^{\circledR}$ (Insect-a-Slip, BioQuip Products Inc., Rancho Dominguez, CA, USA) to render traps more slippery and hence increase trapping efficiency (Graham et al., 2010). In order to collect live beetles, traps were modified by fitting 5-1 plastic collection jars to the bottom of the traps, with holes punched in the jar bottoms for drainage. We hung traps from inverted L-shaped PVC pipe hangers with the trap bases $\sim 50 \mathrm{~cm}$ above ground. Traps were baited with absolute ethanol $(100 \mathrm{ml})$ dispensed from a clear low-density polyethylene press-seal sachet $(10 \times 14 \mathrm{~cm}, 80 \mu \mathrm{m}$ wall thickness, TalgeQualidade e Segurança, Balneário Camboriú, SC, Brazil). Lures were suspended in the open central slot of the panel traps. We deployed four traps on a farm located in Valentim Gentil, SP, Brazil $\left(20^{\circ} 22^{\prime} 17.7^{\prime \prime} \mathrm{S}, 50^{\circ} 04^{\prime} 46.6^{\prime \prime} \mathrm{W}\right)$, which contains fragments of Cerrado or "Brazilian Savanna" (sensu Goodland, 1971) mixed with pastureland. Because we had captured adults of $A$. distinctus and $A$. electus at the same site with light traps in a previous study intended for other purposes, we inferred that these species were probably nocturnal. Therefore, traps were checked for beetles daily soon after sunrise from 20 September to 10 October 2015. Twelve adults (seven females and five males) of A. distinctus and nine adults (five females and four males) of $A$. electus were trapped. Beetles were sexed by the length of the antennae relative to the body; antennae are markedly longer than the length of the body in males but not females (Gahan and Arrow, 1903). The sexes were held separately in $0.2-1$ plastic containers and shipped overnight to the Laboratory of Chemical Ecology and Insect Behavior at the University of São Paulo, Piracicaba, SP, Brazil ( $\sim 400 \mathrm{~km}$ distance). There, beetles were allowed at least 48 $\mathrm{h}$ to acclimate under laboratory conditions $\left(23 \pm 2{ }^{\circ} \mathrm{C}, 60 \pm 10 \%\right.$ $\mathrm{RH}, \sim 5,000$ lux light intensity, and light:dark regime of 12:12 h) prior to being used for collection of headspace volatiles. Beetles were provided with $10 \%$ sucrose solution as nourishment, in glass vials $(7.5 \mathrm{~cm}$ long $\times 1 \mathrm{~cm}$ id) plugged with cotton rolls.

Headspace volatiles were collected from individual beetles, or from pairs of the same species and sex, in custom made $0.5-1$ cylindrical glass chambers. A vial containing $10 \%$ sucrose solution provided nutrition. Collectors consisted of glass pipettes $(8.5 \mathrm{~cm}$ long $\times 0.5 \mathrm{~cm} \mathrm{id})$ containing $150 \mathrm{mg}$ of $80 / 100$ mesh HayeSep ${ }^{\circledR}$ Q (Supelco, Bellefonte, PA, USA), a generic adsorbent for trapping volatile organic compounds such as pheromones, held in place with glass wool plugs. The collector was fastened to the chamber outlet with a Teflon screw cap. Chambers were flushed with charcoal-filtered air at a flow rate of $\sim 300 \mathrm{ml} / \mathrm{min}$. Beetle volatiles were collected continuously for $48 \mathrm{~h}$ under the environmental conditions described above, and individual beetles of both sexes were aerated 1-3 times. Aerations of chambers with sugar feeders but without beetles were run in parallel as controls for system contaminants. Volatiles were rinsed from collectors into silanized glass vials using four successive $0.25-\mathrm{ml}$ aliquots of methylene chloride collected into one vial. The resulting extracts were stored at $-30^{\circ} \mathrm{C}$ until analysis.

Aeration extracts were first analyzed by gas chromatographyflame ionization detection (GC-FID) with a Shimadzu GC2010 gas chromatograph (Shimadzu Corp., Kyoto, Japan) fitted with an HP5-MS capillary column $(30 \mathrm{~m} \times 0.25 \mathrm{~mm}$ i.d. $\times$ $0.25 \mu \mathrm{m}$ film; Agilent Scientific, Santa Clara, CA, USA). One microliter aliquots were injected in splitless mode with an injector temperature of $250^{\circ} \mathrm{C}$ and helium as carrier gas with a linear velocity of $25 \mathrm{~cm} / \mathrm{sec}$, and with the purge valve opened after $1 \mathrm{~min}$. The GC oven was programmed from $35^{\circ} \mathrm{C}$ for 1 min, increased to $40^{\circ} \mathrm{C}$ at $2^{\circ} \mathrm{C} / \mathrm{min}$ (hold for $1 \mathrm{~min}$ ), and then increased to $250^{\circ} \mathrm{C}$ at $10^{\circ} \mathrm{C} / \mathrm{min}$ (hold for $10 \mathrm{~min}$ ). Ratios of compounds were estimated from the integrated peak areas, and have not been corrected for the FID relative response factors. Extracts which contained sex-specific compounds were shipped to the University of California, Riverside, USA, where they were re-analyzed in splitless mode with an Agilent 7820A GC coupled to an Agilent 5977E mass selective detector (GC-MS), using an HP-5 column (same dimensions as above), and a temperature program of $40^{\circ} \mathrm{C} / 1 \mathrm{~min}, 10^{\circ} \mathrm{C} / \mathrm{min}$ to $280^{\circ} \mathrm{C}$ (hold for $10 \mathrm{~min}$ ). Helium was used as carrier gas, with a linear velocity of 37 $\mathrm{cm} / \mathrm{s}$. An aliquot was also analyzed on a midpolarity DB-17 column $(25 \mathrm{~m} \times 0.20 \mathrm{~mm}$ i.d., $0.33 \mu \mathrm{m}$ film; J\&W Scientific, Folsom, CA, USA) using the same temperature program as above. Tentative identifications of compounds were confirmed by matching their retention times and mass spectra with those of authentic standards. The absolute configuration of the insectproduced 3-hydroxyhexan-2-one was determined by analyses of extract aliquots on a Hewlett-Packard 5890 GC fitted with a Cyclodex-B GC column $(30 \mathrm{~m} \times 0.25 \mathrm{~mm}, 0.25 \mu \mathrm{m}$ film, J\&W Scientific) programming from $50^{\circ} \mathrm{C} / 1 \mathrm{~min}, 5^{\circ} \mathrm{C} / \mathrm{min}$ to $200^{\circ} \mathrm{C}$, and with injector and detector temperatures of 100 and $200^{\circ} \mathrm{C}$, respectively. Configurations were confirmed by coinjection of extracts with authentic standards of the two enantiomers (Hanks and Millar, 2016).

In a follow-up experiment, one set of traps baited with racemic 3-hydroxyhexan-2-one, 1-(1H-pyrrol-2-yl)-1,2-propanedione, or a 2:1 blend of the two (see below for trap and lure details) were deployed at the experimental site on 22 October 2016 to capture more beetles alive for collection and analysis of headspace volatiles, as described above. Traps were checked for beetles daily for 2 weeks. In addition to $A$. distinctus and A. electus, these traps yielded at least five individuals of each sex of the cerambycine species Ambonus interrogationis (Blanchard), Amorupi fulvoterminata (Berg), Chrysoprasis aurigena (Germar), Itaclytus olivaceus (Laporte \& Gory), Neoclytus pusillus (Laporte \& Gory), Orthostoma abdominale (Gyllenhal), Sphaerion inerme White, Stizocera consobrina Gounelle, and Uncieburia nigricans (Gounelle) (Table 1). We analyzed the sex-specific volatiles produced by these species, except for A. fulvoterminata and $S$. consobrina, because none of the captured specimens of 
TABLE 1 | Mean ( \pm 1 SE) number per replicate of adults of other cerambycid species in the subfamily Cerambycinae that were caught in the field bioassay of possible attractant pheromones produced by males of Ambonus distinctus and Ambonus electus.

\begin{tabular}{|c|c|c|c|c|c|c|c|c|}
\hline \multirow[t]{2}{*}{ Tribe/species } & \multirow{2}{*}{$\begin{array}{l}\text { Total no. beetles } \\
\text { (reps.) }^{\mathrm{a}}\end{array}$} & \multirow{2}{*}{$\begin{array}{l}\% \text { Females } \\
(P \text {-value })^{\mathrm{b}}\end{array}$} & \multicolumn{5}{|c|}{ Treatments } & \multirow[t]{2}{*}{ Friedman's $Q^{\mathrm{C}}$} \\
\hline & & & C6-ketol & Pyrrole & $\begin{array}{l}\text { C6-ketol } \\
\text { +pyrrole }\end{array}$ & $\begin{array}{l}\text { C6-ketol + pyrrole + } \\
\text { thiopropanol }\end{array}$ & Control & \\
\hline \multicolumn{9}{|l|}{ CLYTINI } \\
\hline $\begin{array}{l}\text { Itaclytus olivaceus (Laporte } \\
\text { \& Gory) }\end{array}$ & $97(40)$ & $33(0.001)$ & $0.7 \pm 0.2 b$ & Oc & $0.7 \pm 0.1 \mathrm{ab}$ & $1.1 \pm 0.2 \mathrm{a}$ & Oc & 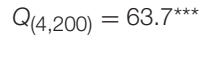 \\
\hline $\begin{array}{l}\text { Neoclytus pusillus (Laporte } \\
\text { \& Gory) }\end{array}$ & $38(20)$ & $34(0.052)$ & $0.9 \pm 0.2 a$ & $0.2 \pm 0.1 b c$ & $0.3 \pm 0.1 \mathrm{abc}$ & $0.7 \pm 0.2 a b$ & Oc & $Q_{(4,100)}=23.4^{\star \star \star}$ \\
\hline \multicolumn{9}{|l|}{ COMPSOCERINI } \\
\hline $\begin{array}{l}\text { Orthostoma abdominale } \\
\text { (Gyllenhal) }\end{array}$ & $94(24)$ & $40(0.063)$ & $1.1 \pm 0.2 \mathrm{a}$ & $0.1 \pm 0.1 b c$ & $1.4 \pm 0.5 \mathrm{ab}$ & $1.2 \pm 0.5 a b c$ & $0.1 \pm 0.1 c$ & $Q_{(4,120)}=24 \cdot 3^{\star \star \star}$ \\
\hline \multicolumn{9}{|l|}{ EBURIINI } \\
\hline $\begin{array}{l}\text { Uncieburia nigricans } \\
\text { (Gounelle) }\end{array}$ & $51(15)$ & $53(0.67)$ & $2.0 \pm 1.0$ & $0.1 \pm 0.1$ & $0.5 \pm 0.2$ & $0.8 \pm 0.5$ & $0.1 \pm 0.1$ & $Q_{(4,75)}=13 \cdot 2^{n s}$ \\
\hline \multicolumn{9}{|l|}{ ELAPHIDIINI } \\
\hline $\begin{array}{l}\text { Ambonus interrogationis } \\
\text { (Blanchard) }\end{array}$ & $113(29)$ & $45(0.30)$ & $1.4 \pm 0.4 a$ & $0.2 \pm 0.1 b$ & $1.1 \pm 0.3 a$ & $1.1 \pm 0.3 a$ & $\mathrm{Ob}$ & $Q_{(4,145)}=44.3^{\star \star \star}$ \\
\hline $\begin{array}{l}\text { Amorupi fulvoterminata } \\
\text { (Berg) }\end{array}$ & $23(12)$ & $52(0.083)$ & $\mathrm{Ob}$ & $1.9 \pm 0.3 a$ & $\mathrm{Ob}$ & $\mathrm{Ob}$ & $\mathrm{Ob}$ & $Q_{(4,60)}=58.2^{\star \star \star}$ \\
\hline Sphaerion inerme White & $96(19)$ & $34(0.002)$ & $1.1 \pm 0.5$ & $1.1 \pm 0.3$ & $2.1 \pm 0.7$ & $0.8 \pm 0.2$ & 0 & $Q_{(4,95)}=14.6^{\mathrm{ns}}$ \\
\hline $\begin{array}{l}\text { Stizocera consobrina } \\
\text { Gounelle }\end{array}$ & $26(15)$ & $65(0.12)$ & $\mathrm{Ob}$ & $1.7 \pm 0.3 a$ & $\mathrm{Ob}$ & $\mathrm{Ob}$ & $\mathrm{Ob}$ & $Q_{(4,75)}=73 \cdot 1^{\star \star \star}$ \\
\hline \multicolumn{9}{|l|}{ HETEROPSINI } \\
\hline $\begin{array}{l}\text { Chrysoprasis aurigena } \\
\text { (Germar) }\end{array}$ & $362(31)$ & $65(<0.001)$ & $1.0 \pm 0.3 \mathrm{bc}$ & $0.2 \pm 0.1 c$ & $5.6 \pm 1.2 a$ & $4.6 \pm 1.3 a b$ & $0.2 \pm 0.1 c$ & $Q_{(4,155)}=51.9^{\star \star \star}$ \\
\hline
\end{tabular}

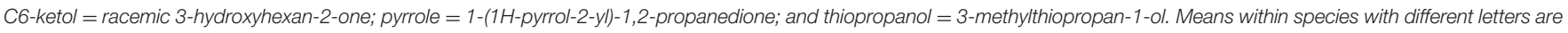
significantly different (Dunn-Nemenyi multiple comparison test, $P<0.05)$.

${ }^{a}$ Number of temporal $\times$ spatial replicates used in statistical analyses.

b Significant differences in the proportion of females trapped from a nominal ratio of 0.5 were calculated using 95\% Clopper-Pearson exact confidence intervals.

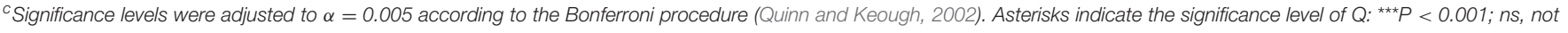
significant $(P>0.005)$.

those species survived long enough to be used for headspace collections. For the remaining species, at least five aeration extracts were made and analyzed for each sex and species.

Voucher specimens of all species have been deposited in the collection of the museum in the Department of Entomology and Acarology, University of São Paulo, Piracicaba, SP, Brazil.

\section{Authentic Standards of Pheromone Components}

Racemic 3-hydroxyhexan-2-one (henceforth "C6-ketol") was purchased from Bedoukian Research (Danforth, CT, USA), 1-(1H-pyrrol-2-yl)-1,2-propanedione (henceforth "pyrrole") was synthesized as described by Zou et al. (2016), and 3methylthiopropan-1-ol (henceforth "thiopropanol") was purchased from Oakwood Chemicals (Estill, SC, USA).

\section{Field Bioassay of the Synthetic Pheromone Candidates}

We field-tested the reconstructed blends of male-specific volatiles (see Section Results) for each of the two Ambonus target species at the site where the beetles originally had been collected (see above) from 16 September to 28 October 2016. We used black flight-intercept panel traps coated with Fluon ${ }^{\circledR}$ as described above, but with trap basins filled with a few centimeters of water to which were added a few drops of detergent and $\sim 25 \mathrm{~g}$ of $\mathrm{NaCl}$ to kill and preserve captured beetles. Lures consisted of resealable polyethylene sachets (Bagettes ${ }^{\circledR}$ model $14770,5 \times 7.5 \mathrm{~cm}, 50 \mu \mathrm{m}$ wall thickness; Cousin Corp., Largo, FL, USA) containing a cotton dental wick. Each lure was loaded with $1 \mathrm{ml}$ of an isopropanol solution of the synthesized pheromone candidates. Treatments ( $\mathrm{mg}$ of compound/lure) were randomly assigned to traps, as follows: (1) C6-ketol (50 mg); (2) pyrrole $(25 \mathrm{mg})$; (3) C6-ketol $(50 \mathrm{mg})+$ pyrrole (25 mg); (4) C6-ketol (50 mg) + pyrrole (25 mg) + thiopropanol $(4 \mathrm{mg})$; and (5) control ( $1 \mathrm{ml}$ of neat isopropanol). Lures were replaced every 2 weeks. Doses and lure replacement times were chosen based on our empirical results from testing cerambycid aggregation-sex pheromones over the past decade using these sachets as release devices. Traps were placed $\sim 15 \mathrm{~m}$ apart in four blocks spaced $\sim 30 \mathrm{~m}$ apart, and each treatment was represented once in each block of traps. Traps were monitored every 2-3 d (total of 19 count dates), with treatments being rotated within blocks at each count to control for positional effects. 


\section{Statistical Analysis}

Differences between treatment means, blocked by location and date, were tested separately for each species using the nonparametric Friedman's Test (PROC FREQ, option CMH; SAS Institute, 2011) because data violated homoscedasticity assumptions of ANOVA (Sokal and Rohlf, 1995). Replicates were defined by block and by collection date. Replicate blocks in which no specimens of the species in question had been caught in any trap were dropped from analyses. In recognition of the multiple statistical tests of treatment effects $(N=11$ analyses; see Section Results), significance levels were adjusted to $\alpha=0.005$ according to the Bonferroni procedure (Quinn and Keough, 2002). Where a significant overall Friedman's test was obtained, pairs of treatment means were compared using the nonparametric Dunn-Nemenyi multiple comparison test, which limits Type I errors to acceptable levels (Zar, 2010; Elliott and Hynan, 2011). Proportions of females trapped were compared to a nominal proportion of 0.5 with $95 \%$ Clopper-Pearson exact confidence intervals (Newcombe, 1998).

\section{Imaging of Sex-Specific Pores on the Prothorax}

Scanning electron microscopy studies had previously shown that adult males of $A$. distinctus have sex-specific pores lying within indentations on the anterior corners of the prothoracic tergum (Ray et al., 2006). Such pores are known to be associated with glands that produce aggregation-sex pheromones (sensu Cardé,
2014) in other species in the Cerambycinae (Ray et al., 2006). To confirm the presence of the male-specific pores in A. distinctus, and check for the pores in A. electus, photographs of the pronota of pinned males and females were taken with a Leica Digital DFC450 camera on a Leica MDG41 stereomicroscope (Leica Microsystems, Heerbrugg, Switzerland). Close-up images were taken at $\sim 130 \mathrm{X}$ magnification.

\section{RESULTS}

\section{Collection and Identification of Volatile Compounds Produced by Beetles}

GC-FID and GC-MS analyses of odors collected from males of $A$. distinctus and $A$. electus revealed three and two peaks, respectively, that were absent in the analogous collections from females (Figure 1). Compounds $\mathbf{1}$ and $\mathbf{3}$ were tentatively identified as previously known cerambycid pheromone components, i.e., C6-ketol and the pyrrole, respectively, from their mass spectra, and the identifications were confirmed by matching their retention times and mass spectra with those of authentic standards. Further analyses of the extracts from each species on a chiral stationary phase Cyclodex B GC column determined that males of both species emitted only (R)-3-hydroxyhexan-2-one. Compound 2, detected only in extracts from $A$. distinctus males, was tentatively identified as 3methylthiopropan-1-ol by matching its mass spectrum to one in the National Institute of Standards (NIS) mass spectral database

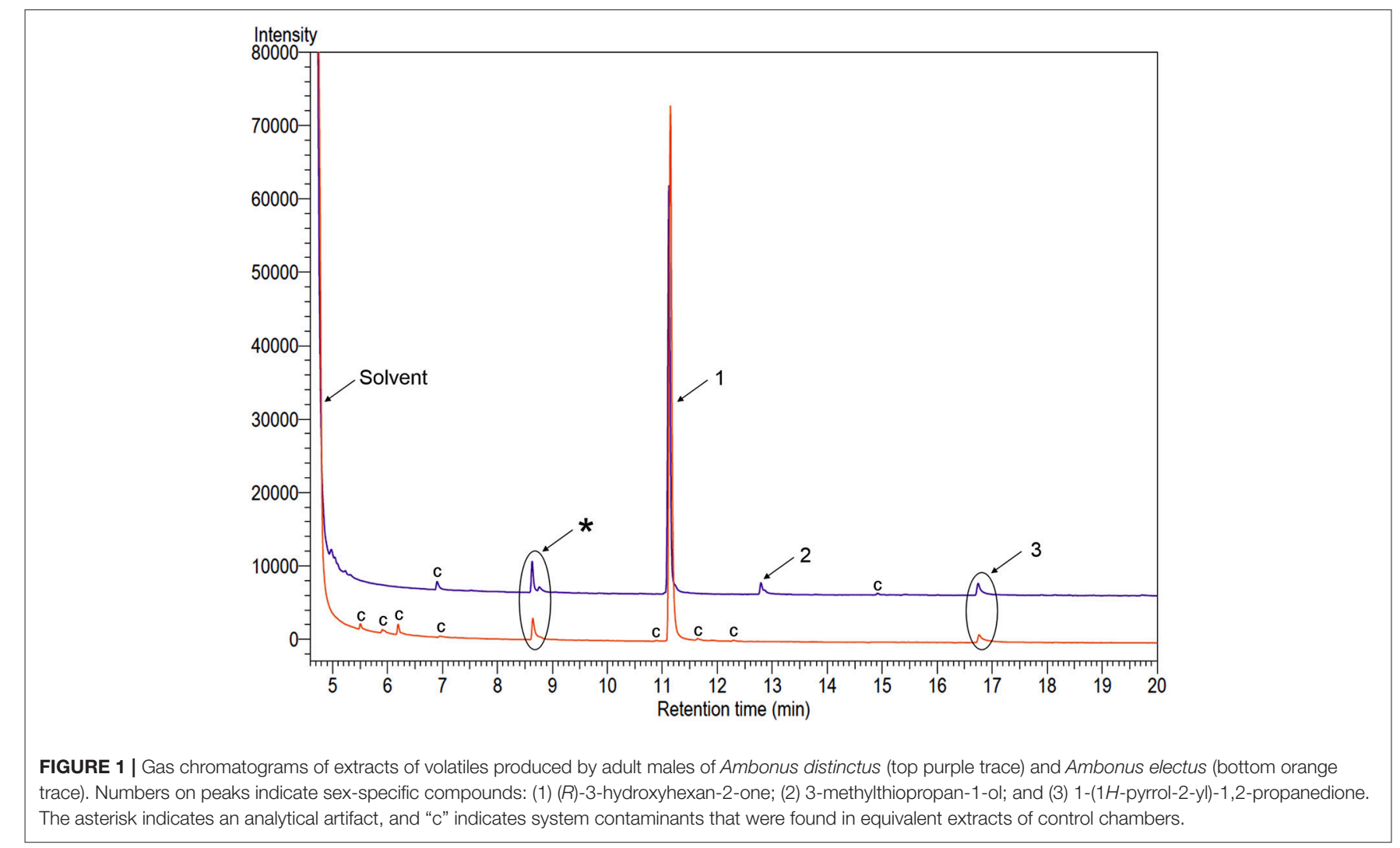


installed on the GC-MS, and the identification was confirmed with an authentic standard, as described above. For A. distinctus, the ratio of $(R)$-3-hydroxyketone: 3-methylthiopropanol: pyrrole was (mean \pm SE) 100: $3.6 \pm 1.0: 3.4 \pm 0.7(N=8)$ in the aeration extracts. For $A$. electus, $(R)$-3-hydroxyketone and the pyrrole were present in a ratio of 100: $5.7 \pm 0.7(N=7)$.

Analyses of headspace volatiles of males of the non-target species determined that $A$. interrogationis, I. olivaceus, N. pusillus, and $O$. abdominale all produced only $(R)$-3-hydroxyhexan-2-one, with no trace of the pyrrole or thiopropanol. Whereas volatiles collected from males of $C$. aurigena, $S$. inerme, and $U$. nigricans all contained sex-specific compounds (identification of the new structures is in progress), none of these species produced the C6-ketol or the pyrrole.

\section{Field Bioassay of the Synthesized Pheromone Candidates}

In total, 264 adults of $A$. distinctus and 276 adults of A. electus were caught in the field bioassay that tested the putative pheromone components. Adults of A. distinctus were attracted in significant numbers only to traps baited with the full three-component pheromone blend (C6-ketol + pyrrole + thiopropanol (Figure 2A). The proportion of females was not significantly different from 0.5 (56\% female; 95\% Clopper-Pearson exact confidence interval: 0.50-0.62; $P=0.067)$. Similarly, adults of $A$. electus were significantly more attracted by their pheromone blend (i.e., C6-ketol and pyrrole) than to individual components and controls (Figure 2B), and the sex ratio of captured beetles was female-biased $(65 \%$ female; 95\% Clopper-Pearson exact confidence interval: 0.57$0.72 ; P<0.001)$. Although this mean was $\sim 50 \%$ higher than that of the blend containing thiopropanol, the difference between the 2-component and the 3-component blend was not statistically significant (Figure 2B).

Another 900 beetles of nine species in five tribes of the Cerambycinae were captured during the course of the field bioassays, among them the congener A. interrogationis (Table 1). Adults of this species were significantly and equally attracted by the treatments containing the C6-ketol alone or the two blends containing the C6-ketol as a component, indicating that the C6ketol was necessary and sufficient to achieve attraction (Table 1). Similarly, I. olivaceus, N. pusillus, and O. abdominale appeared to be attracted by the C6-ketol or blends containing the C6-ketol (Table 1).

In contrast, adults of $C$. aurigena were most attracted to the two blends containing the C6-ketol and the pyrrole, with the two component blend of the C6-ketol and pyrrole being significantly more attractive than either component alone (Table 1). This was unexpected because neither of these compounds were among those detected in analyses of headspace volatiles from male $C$. aurigena (see above). In addition, adults of A. fulvoterminata and S. consobrina were attracted only to traps baited with the pyrrole alone, with no beetles being caught in traps baited with blends of the pyrrole with the C6-ketol, or with the C6-ketol and thiopropanol. Finally, there were no statistically discernable treatment effects for $U$. nigricans

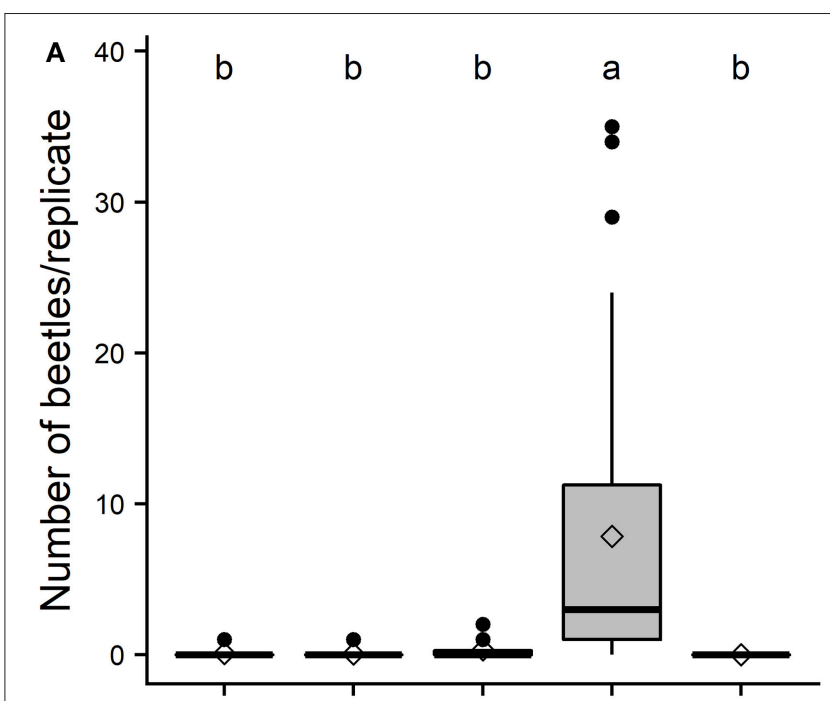

B

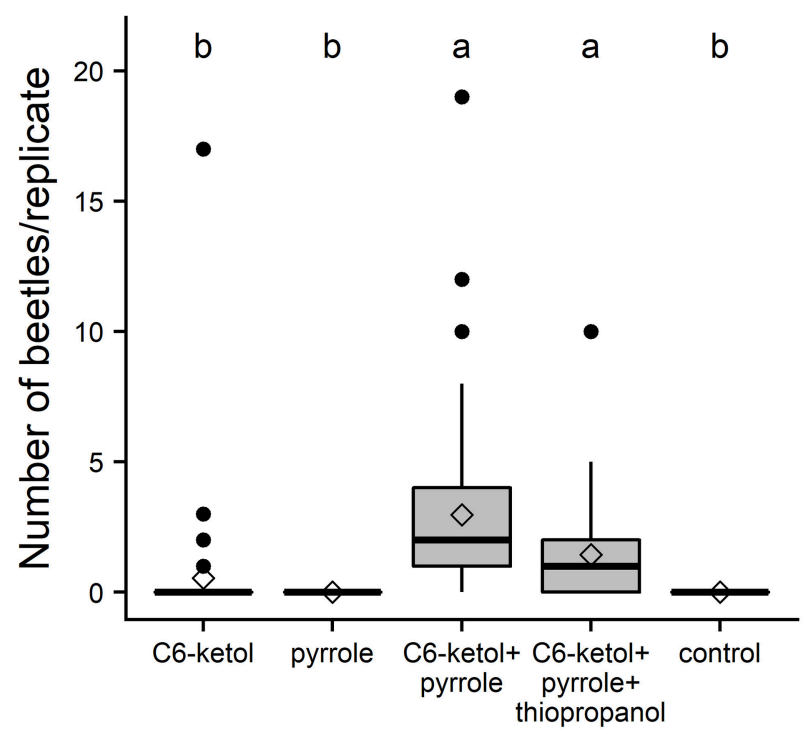

Treatments

FIGURE 2 | Box-and-whisker plots of numbers of adult Ambonus distinctus (A) and Ambonus electus (B) that were caught per replicate in field bioassays of potential pheromones produced by conspecific males. Boxes show the upper $(75 \%)$ and the lower (25\%) percentiles of the data. The horizontal line and diamond within a box represent the median and mean, respectively. Whiskers indicate the highest and lowest values respectively, and dots indicate outliers. C6-ketol = racemic 3-hydroxyhexan-2-one; pyrrole $=$

1-(1H-pyrrol-2-yl)-1,2-propanedione; thiopropanol = 3-methylthiopropan-1-ol. Means significantly different: Friedman's $Q_{(4,160)}=105.9, P<0.001(N=32)$, and $Q_{4,280}=142.2, P<0.001(N=52)$, respectively. Means with different letters are significantly different (Dunn-Nemenyi multiple comparison test, $P<$ 0.05).

and S. inerme, despite there being totals of 96 and 50 beetles caught by baited traps compared to 0 and 1 in controls, respectively. 


\section{Imaging of Sex-Specific Pores on the Prothorax}

Photographic examination of the prothoraces of beetles confirmed that males of $A$. distinctus had the presumed pheromone pores on the tergum, and also demonstrated the presence of analogous male-specific pores on the tergum of male A. electus (Figure 3).

\section{DISCUSSION}

Production of pheromones by males of $A$. distinctus and $A$. electus is consistent with the presence of sex-specific pores on the prothoracic tergum, because analogous pores have been correlated with pheromone production in other species in the subfamily Cerambycinae (Ray et al., 2006; Hoshino et al., 2015). Attraction of both sexes of $A$. distinctus and A. electus to traps baited with reconstructed blends of the compounds produced by conspecific males confirmed that males of both species do indeed produce aggregation-sex pheromones, analogous to pheromones produced by other cerambycine species, and by species in the subfamilies Lamiinae and Spondylidinae (reviewed by Millar and Hanks, 2017). Moreover, A. distinctus and A. electus share two pheromone components $[(R)$-3-hydroxyhexan-2-one and the pyrrole], providing a further example of conservation of pheromone structures between two closely-related species (Millar and Hanks, 2017). However, males of A. distinctus produced an additional minor pheromone component, the thiopropanol, which was a crucial synergist in its pheromone blend. This compound represents an entirely novel structure among the cerambycid pheromones that have been identified so far, and it is likely to be important in maintaining reproductive isolation between these two sympatric and synchronous species. That is, A. distinctus would not be cross-attracted to A. electus males which do not produce this crucial synergist. Conversely, the data suggest that the presence of the thiopropanol in a blend might inhibit attraction of A. electus. Specifically, although the two treatments were not significantly different, the raw data suggests that the three-component blend attracted about half as many A. electus as the 2-component blend of the C6-ketol and pyrrole. Several other examples of minor components in cerambycid pheromone blends playing a role in reproductive isolation of related species have been reported (Mitchell et al., 2015; Meier et al., 2016).

The sex ratio of adult A. electus in our trap catches was female biased ( 1.9:1), whereas the sex ratio of trapped A. distinctus was $\sim 1: 1$. However, without some independent measure of the sex ratio of the field populations during the course of the bioassay, it is not possible to determine whether the responses of A. electus to the pheromone blends were biased toward females.

Nine other cerambycid species were captured during the field bioassays, including the congener A. interrogationis. Analysis of headspace volatiles of males of this species showed that they produce (R)-3-hydroxyhexan-2-one, providing an explanation for their attraction to traps containing C6-ketol as a single

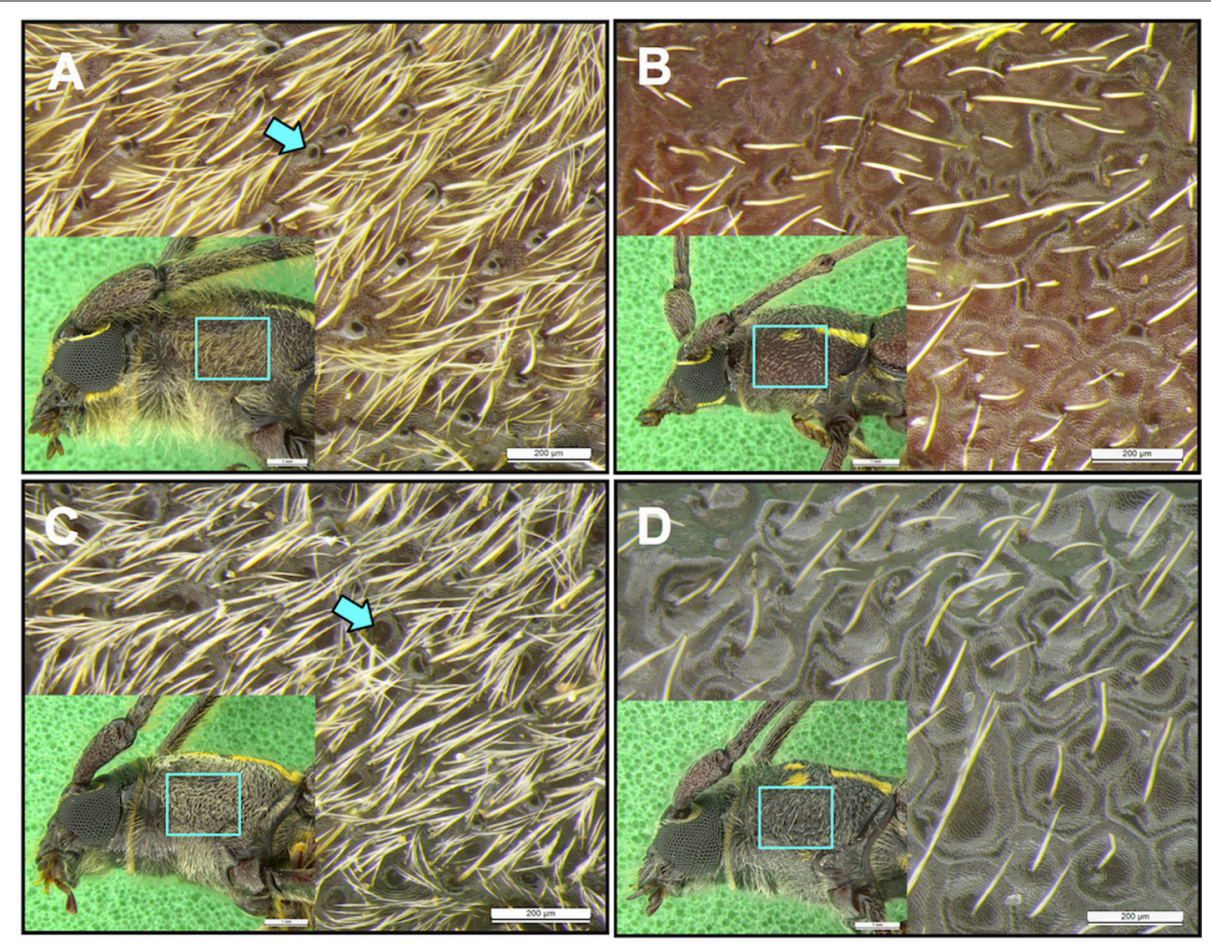

FIGURE 3 | Sexual dimorphism in pronotal pores in Ambonus distinctus and Ambonus electus. Close-up of the anterior corner of the tergum of (A) male and (B) female $A$. distinctus, and (C) male and (D) female A. electus. Males of both species have sex-specific pores (as shown by arrows) that are absent in females, and a higher density of hairs. 
component or as a blend with the thiopropanol and/or the pyrrole. There was no indication that the latter two compounds were inhibitory, because all three lures containing the C6-ketol were equally attractive to $A$. interrogationis. Similarly, males of I. olivaceus, N. pusillus, and O. abdominale all produced (R)-3hydroxyhexan-2-one, and adults of these species were attracted to lures containing the C6-ketol as a single component or in blends. The fact that these sympatric species all appear to be sharing the C6-ketol as a single pheromone component suggests that there must be other mechanisms to minimize cross-attraction among them, such as differences in diel activity periods. That is, it must be remembered that the synthetic lures release pheromone continuously, whereas it is very likely that males of the various species only release and respond to pheromones during species-specific time windows. Furthermore, synergism of the pheromones with different host plant volatiles (Collignon et al., 2016; Hanks and Millar, 2016), and species-specific contact sex pheromones present in the cuticular lipids of females (Ginzel, 2010) would provide additional mechanisms contributing to reproductive isolation among the various species.

In contrast, none of the pheromone components identified in extracts from $A$. distinctus and A. electus were found in equivalent extracts from male C. aurigena, S. inerme, or $U$. nigricans, even though $C$. aurigena in particular was strongly attracted by the blend of C6-ketol and pyrrole (Table 1). These data support the hypothesis that some cerambycid species eavesdrop on the pheromone communication of other guild members, exploiting the signals of heterospecifics as a means of locating hosts suitable for mating and oviposition (see Hanks and Millar, 2013). In addition, males and females of A. fulvoterminata and S. consobrina were attracted specifically to traps baited with the pyrrole as a single component, indicating both that this compound is a potential pheromone candidate for these species, and that the C6-ketol completely inhibits attraction. Taken together, these results suggest that the C6-ketol and the pyrrole, as individual components or in blends with each other and/or with other components, mediate the behaviors of a number of sympatric species native to South America. Further research to fully characterize the semiochemicals used by each species, and to assess possible mechanisms that minimize cross attraction among heterospecifics, should reveal how multiple species are able to coexist despite similarities in their pheromones, their hosts, and their seasonal activity periods.

In summary, we have presented evidence that $(R)-3$ hydroxyhexan-2-one is the dominant or in some cases possibly sole component of the attractant pheromones emitted by males of six South American cerambycid species. This compound appears to be very widespread among species in the subfamily Cerambycinae, now having been shown to be a pheromone

\section{REFERENCES}

Cardé, R. T. (2014). Defining attraction and aggregation pheromones: teleological versus functional perspectives. J. Chem. Ecol. 40, 519-520. doi: 10.1007/s10886-014-0465-6

Collignon, R. M., Swift, I. P., Zou, Y., McElfresh, J. S., Hanks, L. M., and Millar, J. G. (2016). The influence of host plant volatiles on the or likely pheromone component of species from all continents except Antarctica (reviewed in Hanks and Millar, 2016). Similarly, the work presented here, together with previous reports of the male-produced pheromones of Allotreus asiaticus (Schwarzer), Callidiellum rufipenne (Motschulsky) (Zou et al., 2016), Callidiellum villosulum (Fairmaire), Semanotus bifasciatus Motschulsky, and Xylotrechus buqueti (Castelnau \& Gory) (Wickham et al., 2016) suggests that the pyrrole represents another highly conserved pheromone structure within the Cerambycinae, now having been found from species from Asia, North and South America, and Europe. It remains to be determined whether the minor pheromone component thiopropanol of $A$. distinctus is relatively unique, like several other pheromones recently identified from South American species [e.g., 10-methyldodecanal in E. vittata (Silva et al., 2016a) and $(6 E, 8 Z)-6,8$-pentadecadienal in C. costata and C. festiva (Silva et al., 2016b)], or whether it too will prove to be a constituent of numerous pheromone blends of species native to several continents.

\section{AUTHOR CONTRIBUTIONS}

WS, LH, JB, YZ, and JM conceived the study and designed the experiments. WS and JB conducted the headspace volatile collections and field bioassays. YZ and JM identified and synthesized the pheromone components. WS and LH performed statistical analysis. WS, LH, and JM contributed to data analysis and manuscript design. All authors contributed to the writing and review of the manuscript.

\section{FUNDING}

São Paulo Research Foundation (FAPESP) (grant \#2013/26936-2) supported WS, INCT-Semioquímicos na Agricultura (FAPESP and CNPq-grants \#2008/57701-2 and \#573761/2008-6, respectively) supported WS and JB, USDA-APHIS grant 158130-1422-CA supported LH and JM, and the Alphawood Foundation of Chicago supported LH.

\section{ACKNOWLEDGMENTS}

The authors gratefully acknowledge Araci R. Silva and Cassio D. Silva, owners of the agricultural property in Valentim Gentil, for allowing us to access the experimental site, and for their invaluable help in field bioassays. A special thank you to Antonio Santos-Silva (Museu de Zoologia da Universidade de São Paulo) for identifying the cerambycid species. The authors also thank Camila M. Costa, Mateus Tonelli, Arodí P. Favaris, and Emiliana M. Romagnoli for assisting with laboratory work.

attraction of longhorn beetles to pheromones. J. Chem. Ecol. 42, 215-229. doi: 10.1007/s10886-016-0679-x

Costa, C. (2000). "Estado de conocimiento de los coleoptera neotropicales," in Hacia un Proyecto CYTED Para el Inventario y Estimación de la Diversidad Entomológica en Iberoamérica: PrIBES-2000, eds F. Martin Piera, J. J. Morrone, and A. Melic (Zaragoza: M3M - Monografias Tercer Milênio), 99-114. 
Duffy, E. A. J. (1957). A Monograph of the Immature Stages of African Timber Beetles (Cerambycidae). London: British Museum (Natural History).

Duffy, E. A. J. (1960). A Monograph of the Immature Stages of Neotropical Timber Beetles (Cerambycidae). London: British Museum (Natural History).

Duffy, E. A. J. (1963). A Monograph of the Immature Stages of Australasian Timber Beetles (Cerambycidae). London: British Museum (Natural History).

Elliott, A. C., and Hynan, L. S. (2011). A SAS ${ }^{\circledR}$ macro implementation of a multiple comparison post hoc test for a Kruskal-Wallis analysis. Comput. Methods Programs Biomed. 102, 75-80. doi: 10.1016/j.cmpb.2010.11.002

Fonseca, M. G., Vidal, D. M., and Zarbin, P. (2010). Male-produced sex pheromone of the cerambycid beetle Hedypathes betulinus: chemical identification and biological activity. J. Chem. Ecol. 36, 1132-1139. doi: 10.1007/s10886-010-9850-y

Gahan, C. J., and Arrow, G. J. (1903). List of the coleoptera collected by Mr. A. Robert at Chapada, Matto Grosso (Percy Sladen expedition to Central Brazil). Proc. Zool. Soc. London 2, 244-258.

Ginzel, M. D. (2010). "Hydrocarbons as contact pheromones of longhorned beetles (Coleoptera: Cerambycidae)," in Insect Hydrocarbons: Biology, Biochemistry and Chemical Ecology, eds G. L. Blomquist and A. G. Bagnères (Cambridge: Cambridge University Press), 375-389.

Goodland, R. (1971). A physiognomic analysis of the 'cerrado' vegetation of Central Brazil. J. Ecol. 59, 411-419. doi: 10.2307/2258321

Graham, E. E., Mitchell, R. F., Reagel, P. F., Barbour, J. D., Millar, J. G., and Hanks, L. M. (2010). Treating panel traps with a fluoropolymer dramatically enhances their efficiency in capturing cerambycid beetles. J. Econ. Entomol. 103, 641-647. doi: 10.1603/EC10013

Graham, E. E., Poland, T. M., McCullough, D. G., and Millar, J. G. (2012). A comparison of trap type and height for capturing cerambycid beetles (Coleoptera). J. Econ. Entomol. 105, 837-846. doi: 10.1603/EC12053

Hanks, L. M., and Millar, J. G. (2013). Field bioassays of cerambycid pheromones reveal widespread parsimony of pheromone structures, enhancement by host plant volatiles, and antagonism by components from heterospecifics. Chemoecology 23, 21-44. doi: 10.1007/s00049-012-0116-8

Hanks, L. M., and Millar, J. G. (2016). Sex and aggregation-sex pheromones of cerambycid beetles: basic science and practical applications. J. Chem. Ecol. 42, 631-654. doi: 10.1007/s10886-016-0733-8

Hanks, L. M., Millar, J. G., Moreira, J. A., Barbour, J. D., Lacey, E. S., McElfresh, J. S., et al. (2007). Using generic pheromone lures to expedite identification of aggregation pheromones for the cerambycid beetles Xylotrechus nauticus, Phymatodes lecontei, and Neoclytus modestus modestus. J. Chem. Ecol. 33, 889-907. doi: 10.1007/s10886-007-9275-4

Hanks, L. M., Reagel, P. F., Mitchell, R. F., Wong, J. C. H., Meier, L. R., Silliman, C. A., et al. (2014). Seasonal phenology of the cerambycid beetles of East Central Illinois. Ann. Entomol. Soc. Am. 107, 211-226. doi: 10.1603/AN13067

Hoshino, K., Nakaba, S., Inoue, H., and Iwabuchi, K. (2015). Structure and development of male pheromone gland of longicorn beetles and its phylogenetic relationships within the tribe Clytini. J. Exp. Zool. B Mol. Dev. Evol. 324, 68-76. doi: 10.1002/jez.b.22606

Meier, L. R., Zou, Y., Millar, J. G., Mongold-Diers, J. A., and Hanks, L. M. (2016). Synergism between enantiomers creates species-specific pheromone blends and minimizes cross-attraction for two species of cerambycid beetles. J. Chem. Ecol. 42, 1181-1192. doi: 10.1007/s10886-016-0782-z

Millar, J. G., and Hanks, L. M. (2017). "Chemical ecology of cerambycid beetles," in Cerambycidae of the World: Biology and Pest Management, ed Q. Wang (Boca Raton, FL: CRC Press), 161-208.

Mitchell, R. F., Graham, E. E., Wong, J. C. H., Reagel, P. F., Striman, B. L., Hughes, G. P., et al. (2011). Fuscumol and fuscumol acetate are general attractants for many species of cerambycid beetles in the subfamily Lamiinae. Entomol. Exp. Appl. 141, 71-77. doi: 10.1111/j.1570-7458.2011.01167.x

Mitchell, R. F., Millar, J. G., and Hanks, L. M. (2013). Blends of (R)-3hydroxyhexan-2-one and alkan-2-ones identified as potential pheromones produced by three species of cerambycid beetles. Chemoecology 23, 121-127. doi: 10.1007/s00049-012-0122-x

Mitchell, R. F., Reagel, P. F., Wong, J. C. H., Meier, L. R., Silva, W. D., MongoldDiers, J., et al. (2015). Cerambycid beetle species with similar pheromones are segregated by phenology and minor pheromone components. J. Chem. Ecol. 41, 431-440. doi: 10.1007/s10886-015-0571-0
Monné, M. A. (2001). Catalogue of the neotropical Cerambycidae (Coleoptera) with known host plant - Part I: Subfamily Cerambycinae, Tribes Achrysonini to Elaphidiini. Publ. Avulsas Mus. Nac. 88, 1-108.

Monné, M. A. (2017). Catalogue of the Cerambycidae (Coleoptera) of the neotropical region. Part I: subfamily Cerambycinae. Available online at: https://cerambyxcat.com/Parte1_Cerambycinae.pdf (Accessed June 10, 2017).

Newcombe, R. G. (1998). Two-sided confidence intervals for the single proportion: comparison of seven methods. Stat. Med. 17, 857-872. doi: 10.1002/(SICI)1097-0258(19980430)17:8\&lt;857 ::AID-SIM777\&gt;3.0.CO;2-E

Quinn, G. P., and Keough, M. J. (2002). Experimental Design and Data Analysis for Biologists. Cambridge: Cambridge University Press.

Ray, A. M., Barbour, J. D., McElfresh, J. S., Moreira, J. A., Swift, I., Wright, I. M., et al. (2012). 2,3-Hexanediols as sex attractants and a female-produced sex pheromone for cerambycid beetles in the prionine genus Tragosoma. J. Chem. Ecol. 38, 1151-1158. doi: 10.1007/s10886-012-0181-z

Ray, A. M., Lacey, E. S., and Hanks, L. M. (2006). Predicted taxonomic patterns in pheromone production by longhorned beetles. Naturwissenschaften 93, 543-550. doi: 10.1007/s00114-006-0142-x

Ray, A. M., Millar, J. G., Moreira, J. A., McElfresh, J. S., Mitchell, R. F., Barbour, J. D., et al. (2015). North American species of cerambycid beetles in the genus Neoclytus share a common hydroxyhexanone-hexanediol pheromone structural motif. J. Econ. Entomol. 108, 1860-1868. doi: 10.1093/jee/tov170

SAS Institute (2011). SAS/STAT 9.3 User's Guide. Cary, NC: SAS Institute Inc.

Schmeelk, T. C., Millar, J. G., and Hanks, L. M. (2016). Influence of trap height and bait type on abundance and species diversity of cerambycid beetles captured in forests of East-Central Illinois. J. Econ. Entomol. 109, 1750-1757. doi: 10.1093/jee/tow102

Silva, A. G. A., Gonçalves, C. R., Galvão, D. M., Gonçalves, A. J. L., Gomes, J., Silva, M. N., et al. (1968). Quarto Catálogo dos Insetos que Vivem nas Plantas do Brasil. Seus Parasitos e Predadores. Rio de Janeiro: Ministério da Agricultura (in Portuguese).

Silva, W. D., Millar, J. G., Hanks, L. M., and Bento, J. M. S. (2016a). 10Methyldodecanal, a novel attractant pheromone produced by males of the South American cerambycid beetle Eburodacrys vittata. PLoS ONE 11:e0160727. doi: 10.1371/journal.pone.0160727

Silva, W. D., Millar, J. G., Hanks, L. M., and Bento, J. M. S. (2016b). (6E,8Z)6,8-Pentadecadienal, a novel attractant pheromone produced by males of the cerambycid beetles Chlorida festiva and Chlorida costata. J. Chem. Ecol. 42, 1082-1085. doi: 10.1007/s10886-016-0742-7

Sokal, R. R., and Rohlf, F. J. (1995). Biometry. New York, NY: W. H. Freeman.

Švácha, P., and Lawrence, J. F. (2014). "Cerambycidae latreille, 1802," in Handbook of Zoology: Arthropoda: Insecta: Coleoptera, Beetles, Vol. 3: Morphology and Systematics (Phytophaga), eds R. A. B. Leschen and R. G. Beutel (Berlin: De Gruyter), 77-177.

Wickham, J. D., Millar, J. G., Hanks, L. M., Zou, Y., Wong, J. C. H., Harrison, R. D., et al. (2016). (2R,3S)-2,3-Octanediol, a female-produced sex pheromone of Megopis costipennis (Coleoptera: Cerambycidae: Prioninae). Environ. Entomol. 45, 223-228. doi: 10.1093/ee/nvv176

Zar, J. H. (2010). Biostatistical Analysis. Upper Saddle River, NJ: Pearson PrenticeHall.

Zou, Y., Rutledge, C. E., Nakamuta, K., Maier, C. T., Hanks, L. M., Richards, A. B., et al. (2016). Identification of a pheromone component and a critical synergist for the invasive beetle Callidiellum rufipenne (Coleoptera: Cerambycidae). Environ. Entomol. 45, 216-222. doi: 10.1093/ee/nvv165

Conflict of Interest Statement: The authors declare that the research was conducted in the absence of any commercial or financial relationships that could be construed as a potential conflict of interest.

Copyright $\odot 2017$ Silva, Zou, Bento, Hanks and Millar. This is an open-access article distributed under the terms of the Creative Commons Attribution License (CC BY). The use, distribution or reproduction in other forums is permitted, provided the original author(s) or licensor are credited and that the original publication in this journal is cited, in accordance with accepted academic practice. No use, distribution or reproduction is permitted which does not comply with these terms. 